\title{
Jumping performance and take-off efficiency correlation with the basic anthropometric parameters in female volleyball players
}

\author{
Soňa Jandová ${ }^{1,2 ⿴ 囗 十 ~}$ \\ ${ }^{1}$ Department of Applied Mechanics, Faculty of Mechanical Engineering, Technical University of Liberec, Liberec, Czech Republic; and \\ ${ }^{2}$ Department of Physical Education, Faculty of Education, Charles University, Prague, Czech Republic
}

\section{Abstract}

Background: Vertical jump height and body height are almost universally recognised as determinant factors in elite volleyball performance. Objective: The purpose of this study was to assess the correlation between basic anthropometric parameters (body height and body weight) and jumping performance in a group of 16 female volleyball players (age $19.14 \pm 5.52$ years, height $1.80 \pm 0.06$ $\mathrm{m}$, weight $69.81 \pm 6.85 \mathrm{~kg}$ ) and in a control group of 15 female university students (age $22.90 \pm 0.83$ years, height $1.70 \pm 0.05 \mathrm{~m}$, weight $61.70 \pm 8.23 \mathrm{~kg}$ ). Methods: The Quattro Jump 9290BA force platform system (Kistler, Winterthur, Switzerland) was used to test jumping performance in single vertical jumps (squat jump, countermovement jump) and 45 -s continuous jumps. In single jumps, jump height was analysed and during the 45 -s continuous jumps the maximal and mean jump height, the average contact time and the fatigue index were evaluated. The efficiency of the conversion of mechanical work into mechanical energy at the moment of takeoff was calculated. Results: No significant influence of body height and body weight was found in the jumping performance in the squat jump and countermovement jump. In continuous jumps, a significant correlation was found between body height and fatigue index in the volleyball players. In the control group, in most of the tests moderate correlation between body height and jump height was observed. In the volleyball players, rather low values of efficiency of take-off $(23.67 \pm 2.64 \%)$ were calculated. The values in the control group were even lower. Conclusions: Nowadays, many volleyball coaches choose individuals mainly according to body height, but it is important that the talent identification process should also consider jumping abilities in the simple jumps and in continuous jumps. All these parameters should help coaches choose the right players for the appropriate position and role in the team.

Keywords: squat jump, countermovement jump, continuous jumps, flight height, body height, body weight

\section{Introduction}

Women's volleyball belongs to popular team sports. Successful performance depends on a combination of many factors like anthropometric, physiological, socio-psychological and technical-tactical parameters (Gabett et al., 2007; Lidor \& Ziv, 2010). Moreover, due to the specificity of volleyball, there are different playing positions, and in volleyball can be seen variability of the morphological structure of players within the team (Malousaris et al., 2008), especially in females (Malá et al., 2010).

According to Santos et al. (2014), the higher the sports achievements are, the more closely related to the athlete's body composition. Volleyball is a sport with particular characteristics, taking into account a height of the net of 2.24 meters for the female and the body height seems to have an important role for talent identification (Giannopoulos et al., 2017). Nowadays, can be seen a trend of change in anthropometry of the top world women's teams (Mielgo-Ayuso, et al., 2015).

When comparing the body weight and height of the female top-level volleyball players, both parameters slightly increased. Bankovic et al. (2018) observed very high muscle mass and a low amount of body fat that it bordered on the minimum for women in a group of top elite women volleyball players who won the silver medal 2016 Rio Olympic Games. Nikolaidis (2013) demonstrated anthropometric parameters' negative role when the higher body mass and body fat percentage values entailed weaker jumping performance results.

Jumping performance in various sports is usually assessed using jumping tests, including single jumps such as the squat jump, countermovement jump, and continuous jumps (Haugen et al., 2021). Vertical jump height is influenced by the production of power using the lower limbs. It is critical for performance in numerous volleyball game actions that involve jumping activities, such as serving, attacking, blocking, and setting (Sheppard et al., 2009).

The single jump seems to be a handy tool for a lower extremity power test (Markovic et al., 2004), and it is widely used to assess jumping performance in volleyball (Sheppard et al., 2012; Ziv \& Lidor, 2010). The continuous jump test is often used by volleyball players and for testing talented individuals involved in anaerobic activities

$\triangle$ Corresponding author: Soňa Jandová, e-mail sona.jandova@tul.cz, ORCID ${ }^{\circledR}$ record https://orcid.org/0000-0003-4459-5248

Article history: Received February 3 2021, Accepted September 14 2021, Published October 112021

Copyright: @ 2021 The Author(s). Published by Palacký University Olomouc. This is an open access article distributed under the terms of the Creative Commons Attribution License (https://creativecommons.org/licenses/by/4.0/), which permits unrestricted use, distribution, and reproduction in any medium, provided the original author and source are credited. This license does not cover any third-party material that may appear with permission in the article. 
(Bencke et al., 2002; Lidor et al., 2005; Nikolaidis \& Ingebrigtsen, 2013).

Based on the study by Skazalski et al. (2018) the volleyball players performed from 47 to 67 maximal jumps per hour depending on player position during a real match.

During vertical jumps, potential energy and kinetic energy are transformed mutually. During the take-off phase muscular work, which is converted into mechanical energy during the flight phase, is performed by the athlete. When an anaerobic performance for CJ is being monitored, take-off efficiency can be monitored as well (Jandova et al., 2017).

Nowadays, there is a trend to select young, tall female players into ambitious teams. Very tall players are usually directed towards the specialisation in the position of middle blocker or spiker. It sometimes happens without considering their jumping abilities, and smaller players play in the defensive libero position (Valleser et al., 2018). Theoretically, if some small players want to hit the ball at the same height as tall players, they need to jump much higher to eliminate the body height difference and the arm length difference. Body height is usually used as a primary selection criterion in talent identification (Vaeyens et al., 2008). The growth of individuals in adolescence takes place at different speeds (Pavillon et al., 2021). It very often happens that talent identification based only on body height may not reveal the perspective of some slow-growing players in that period. Nikolaidis et al. (2015) reported that the athletes who have the best vertical jump performance reach maturity later. One of the determinant factors in elite volleyball performance is vertical jump height (Sheppard et al., 2012). It seems very important to use both the criteria, such as basic anthropometric parameters and jumping abilities, during talent identification selection processes.

We assume that knowledge of both these parameters is desirable, and selecting talented individuals should not only be based on body height, as it happens in Czech volleyball teams. Being aware of a correlation between these parameters is of great practical importance for volleyball coaches. We also assume that the endurance level in jumping abilities represented by the fatigue index is the highest in a group of spikers. Therefore, this study aimed to analyse the relationship between jumping performance and basic anthropometric parameters such as body height, body weight in a group of female volleyball players concerning their position in the team (blocker, setter, spiker, libero) and a control group of university students.

\section{Methods}

\section{Participants}

Thirty-one female participants voluntarily participated in this study. Two groups of these participants were tested separately for squat jump (SJ), countermovement jump $(\mathrm{CMJ})$ and continuous jumps (CJ). In the first group, 16 female volleyball players (VOL) from the same sports club were tested (age $19.14 \pm 5.52$ years, height $1.80 \pm 0.06 \mathrm{~m}$, weight $69.8 \pm 6.85 \mathrm{~kg}$ ). The second group was a control group $(\mathrm{CON})$ of 15 healthy female university students (age $22.9 \pm 0.83$ years, height $1.70 \pm 0.05 \mathrm{~m}$, weight: $61.7 \pm 8.23 \mathrm{~kg}$ ). The players had a mean of six years of experience with volleyball training (four years at least). All players performed four days/week training sessions in the club, which took part in the Czech national premier league in 2018. Students attended physical activity lessons two hrs/week at the university. The exclusion criteria for both groups included a previous musculoskeletal injury within one year and suffering from musculoskeletal pain that could limit the range of motion of their body or extremities. All subjects signed an informed consent form of voluntary participation in the proposed study. The study was approved by the Institutional Review Board for the Testing of Human Subjects and was performed in accordance with the ethical standards of the Helsinki Declaration. Parents signed consent for individuals under 18 .

\section{Data collection and protocol}

Quattro Jump 9290BA force platform (Kistler, Winterthur, Switzerland) was used to test jumping performance in single vertical jumps (squat jump, countermovement jump). Efficiency and fatigue index were observed during 45-s continuous jumps with hands-on-hips as a variation of the Bosco test (Bosco et al., 1983).

The participants were first familiarized with the measurement protocol and subsequently signed an informed consent form. At the beginning of data collection, anthropometric data were recorded. Height was measured with a portable A 213 anthropometer (Trystom, Olomouc, Czech Republic) and body weight using an electronic scale (Amboss, New York, NY, USA). All participants were asked for their age and position in the field. After appropriate warm-up (10 min), participants were tested in SJ and CMJ. The order of the test was random. During SJ, they were instructed to jump as high as possible, starting from a semisquat position, and hands were on their hips (according to the Kistler platform software instruction). During CMJ, participants started from a standing position followed by a downward movement and then continued with the take-off. The hands were on the hips, similar to SJ again, according to Kistler platform software instruction. The rest between the jumps was $30 \mathrm{~s}$. Two attempts of SJ and also of CMJ were measured. As the CON group participated in the testing, more attempts of SJ and CMJ would be demanding. It would probably influence the following CJ test. Only the higher jump of two attempts was analysed.

After a 5-min rest, athletes were asked to perform 45-s continuous vertical jumps (CJ) with $90^{\circ}$ knee bending and with their hands on their hips. The aim was to jump as high as possible during $45 \mathrm{~s}$. We shortened the test compared to LaPorta et al. (2013) concerning the fact that CON would not be able to pass the 60-s test, and also with respect to the fact, that female volleyball players do not usually perform so many jumps during their game (Skazalski et al., 2018).

\section{Calculated parameters}

During SJ and CMJ test, a vertical force was recorded with a force platform, and from this variable height of the jump (hj) was calculated. During 45-s CJ, these variables were 
evaluated: the maximal height of the jump $\left(\mathrm{hj}_{\max }\right)$, mean height of the jump $\left(\mathrm{hj}_{\mathrm{ave}}\right)$, the average contact time $\left(\mathrm{CT}_{\text {ave }}\right)$ and fatigue index (FI). The efficiency $(\eta)$ of the conversion of mechanical work into mechanical energy at the moment of take-off was calculated as follows (Jandova \& Janura, 2019):

$$
\left.\eta=\mathrm{W}_{2} / \mathrm{W}_{1}=\left(\mathrm{m}^{*} \mathrm{~g}^{*} \mathrm{hj}\right) / \mathrm{m}^{*} \mathrm{P}_{\mathrm{BW}}{ }^{*} \mathrm{CT}\right)
$$

$\eta$ is the efficiency, $W_{1}$ represents a subject's power input calculated as the product of a subject's body weight $(\mathrm{m}$, in $\mathrm{kg}$ ), a subject's performance per kilogram of body weight $\left(\mathrm{P}_{\mathrm{BW}}\right.$, in W· $\left.\mathrm{kg}^{-1}\right)$, and the length of contact time with a force plate (CT, in s). W represents a subject's power output, which is equal to the potential energy at the highest jump point. It is calculated as the product of a subject's body weight $(\mathrm{m}$, in $\mathrm{kg})$, the gravitational acceleration $(\mathrm{g}=9.81$ $\left.\mathrm{kg} \cdot \mathrm{m} \cdot \mathrm{s}^{-2}\right)$, and the jump height (hj, in $\left.\mathrm{m}\right)$.

\section{Statistical analysis}

Statistical analysis of the collected data was performed using the Statistica program (Version 12; StatSoft, Tulsa, OK, USA). The normality of data was confirmed using the Shapiro-Wilk test. Mann-Whitney $U$ test was used to analyse the differences between VOL and CON. Spearman's correlation coefficients were used to quantify relationships between age and anthropometric parameters body height $(\mathrm{BH})$, body weight $(B W)$ and calculated parameters $\left(\mathrm{hj}_{\max }, \mathrm{hj}_{\text {ave }}, \mathrm{CT}_{\text {ave' }}\right.$, $\mathrm{FI}$ and $\eta$ ) of the vertical jump performance. Effect size using coefficient $r$ was evaluated $(r=.1$, small effect; $r=.3$, moderate effect; $r=.5$, large effect). A linear regression analysis was performed using the age and basic anthropometric parameters as predictors of vertical jumps performance:

$$
\mathrm{Y}=b_{0}+b_{1} \mathrm{BH}+b_{2} \mathrm{BW}+b_{3} \text { Age. }
$$

A partial correlation coefficient was used to determine the correlation, excluding the effect of other parameters contained in the model. All the data are presented as mean \pm standard deviation. The level of significance was set to $p \leq .05$.

\section{Results}

\section{Anthropometric parameters}

The results from the basic anthropometric measurement are shown in Table 1 . BH was significantly higher in the VOL group than in the CON group $(p<.001)$, and BW was significantly higher in VOL too $(p=.01)$.

\section{Single vertical jumps}

The results from the single vertical jumps (SJ and CMJ) are shown in Table 2. In the VOL group, the hj values in SJ ranged from $33.5 \mathrm{~cm}$ to $42.2 \mathrm{~cm}$ and in CON from $23.9 \mathrm{~cm}$ to $41.3 \mathrm{~cm}$. The values in VOL were significantly higher $(p=.002)$. The highest hj was observed in liberos and the weakest results in blockers (Table 2). According to the linear regression model (Formula 2, Table 3) and correlation analysis (Table 4), no influence of $\mathrm{BH}$ or BW on the jumping performance in VOL was confirmed.

The hj for CMJ was in the VOL group higher than in CON $(p=.001)$. The range in VOL was 33.2-44.7 $\mathrm{cm}$. These values were higher than those for SJ when the jump was performed without knee pre-stretch movement. According to the statistics, there were only very low correlations between anthropometric parameters and jumping performance parameters in VOL. The pre-stretch effect was approximately 5\%. The best results were in spikers $(n=6)$ and similar to SJ the weakest hj was observed in blockers $(n=4)$. The hj range in the CON group was $26.5-42.5 \mathrm{~cm}$. Here was the pre-stretch effect approximately $3 \%$. The influence of age on hj was not confirmed neither in SJ nor CMJ.

\section{Continuous vertical jumps}

Results of the jumping performance for CJ (Table 2) showed differences between VOL and CON groups. In both performance parameters $\left(\mathrm{hj}_{\max }, \mathrm{hj} \mathrm{j}_{\text {ave }}\right)$ were values of VOL higher than in CON $(p<.001)$. The highest $\mathrm{hj}_{\max }$

\begin{tabular}{|c|c|c|c|c|c|c|c|}
\hline Variable & $\operatorname{VOL}(n=16)$ & $\operatorname{CON}(n=15)$ & $p$ & Setter $(n=4)$ & Blocker $(n=4)$ & Spiker $(n=6)$ & Libero $(n=2)$ \\
\hline Body height (m) & $1.80 \pm 0.06$ & $1.70 \pm 0.05$ & $<.001$ & $1.78 \pm 0.02$ & $1.84 \pm 0.04$ & $1.79 \pm 0.04$ & $1.70 \pm 0.01$ \\
\hline Body weight (kg) & $69.76 \pm 6.85$ & $61.73 \pm 8.23$ & .008 & $71.00 \pm 3.94$ & $70.40 \pm 7.17$ & $71.17 \pm 6.84$ & $61.50 \pm 4.50$ \\
\hline Age (years) & $19.14 \pm 5.52$ & $22.87 \pm 0.83$ & .015 & $17.43 \pm 2.85$ & $19.30 \pm 4.31$ & $20.92 \pm 6.60$ & $20.25 \pm 5.75$ \\
\hline
\end{tabular}

Table 1 Basic anthropometric parameters

Note. $\mathrm{VOL}=$ volleyball players; $\mathrm{CON}=$ control group .

\begin{tabular}{|c|c|c|c|c|c|c|c|}
\hline Variable & VOL $(n=16)$ & $\operatorname{CON}(n=15)$ & $p$ & Setter $(n=4)$ & Blocker $(n=4)$ & Spiker $(n=6)$ & Libero $(n=2)$ \\
\hline SJ hj (cm) & $38.41 \pm 2.69$ & $32.15 \pm 16.58$ & .002 & $37.93 \pm 3.02$ & $37.40 \pm 3.23$ & $38.93 \pm 1.69$ & $40.3 \pm 1.20$ \\
\hline CMJ hj (cm) & $39.85 \pm 3.28$ & $33.59 \pm 5.02$ & .001 & $39.75 \pm 3.45$ & $37.94 \pm 3.97$ & $41.65 \pm 1.24$ & $41.40 \pm 0.20$ \\
\hline $\mathrm{CJ} \mathrm{hj} \mathrm{m}_{\max }(\mathrm{cm})$ & $37.37 \pm 3.85$ & $30.17 \pm 4.85$ & .001 & $33.30 \pm 3.52$ & $37.43 \pm 2.25$ & $39.15 \pm 2.87$ & $40.05 \pm 3.05$ \\
\hline $\mathrm{CJ} \mathrm{hj} \mathrm{ave}_{\text {a }}(\mathrm{cm})$ & $31.11 \pm 3.56$ & $24.93 \pm 5.0$ & .001 & $27.35 \pm 4.47$ & $32.30 \pm 1.61$ & $32.63 \pm 2.09$ & $31.65 \pm 2.25$ \\
\hline $\mathrm{CJ} \mathrm{CT}_{\text {ave }}$ (ms) & $795 \pm 108$ & $895 \pm 153$ & .04 & $791 \pm 102$ & $856 \pm 65$ & $786 \pm 128$ & $713 \pm 43$ \\
\hline CJ n (\%) & $23.67 \pm 2.64$ & $19.83 \pm 3.17$ & .01 & $24.73 \pm 2.67$ & $21.65 \pm 1.60$ & $24.66 \pm 2.48$ & $23.10 \pm 2.10$ \\
\hline CJ FI (\%) & $72.73 \pm 7.17$ & $75.06 \pm 9.71$ & .69 & $74.30 \pm 6.90$ & $76.95 \pm 4.35$ & $73.18 \pm 4.80$ & $59.80 \pm 0.30$ \\
\hline
\end{tabular}

Table 2 Results from jumping tests

Note $\mathrm{VOL}=$ volleyball players; $\mathrm{CON}=$ control group; $\mathrm{SJ}=$ squat jump; $\mathrm{CMJ}=$ countermovement jump; $\mathrm{CJ}=$ continuous jumps; hj $=$ height of the jump; $\mathrm{CJ}$ hj ${ }_{m a x}=$ maximal height of the jump in the $\mathrm{CJ} ; \mathrm{CJ} \mathrm{hj}_{\text {ave }}=$ average height of the jump in the $\mathrm{CJ} ; \mathrm{CJ} \mathrm{CT}_{\text {ave }}=$ average contact time in the $\mathrm{CJ} ; \mathrm{CJ} \eta=$ efficiency in the $\mathrm{CJ}$; $\mathrm{CJ} \mathrm{FI}=$ fatigue index in the $\mathrm{CJ}$. 
were in the position of liberos $(n=2)$, and the weakest results in setters $(n=4)$. In hj ${ }_{\text {ave }}$ were spikers slightly better than liberos and setters were the weakest. Besides, contact time $\mathrm{CT}_{\text {ave }}$ was shorter in VOL than in $\mathrm{CON}(p=.04)$ and the shortest time was observed in liberos.

According to the correlation analysis (Table 5), we found only a correlation between FI and $\mathrm{BH}$ in the VOL group and between FI and BMI in the CON group, and there were no correlations with $\mathrm{BH}, \mathrm{BW}$ neither in performance parameters nor in $\mathrm{CT}_{\text {ave }}$ in both groups. Evaluation of effect size in VOL showed a strong effect of $\mathrm{BH}$ and $\mathrm{BW}$ to FI and in CON group a moderate effect of $\mathrm{BH}$ to $\mathrm{hj}_{\max }$ and FI and strong effect to $\mathrm{hj}_{\text {ave }}$. In addition, the effect size of BW to hj $j_{\max }, h_{\text {ave }}$ and was moderate in CON too. The effect size of $\mathrm{BH}$ and $\mathrm{BW}$ to other parameters was very low in both groups.

Fatigue gradually increased during the 45-s CJ test in both groups, which could be observed in an ongoing reduction of hj. Concerning the mean values estimated for the FI of the continuous test, values of $72.7 \pm 7.17 \%$ in VOL were found. The values in CON were slightly higher $(75.06 \pm 9.71 \%)$ but not significantly $(p=.693)$. The highest values of FI were found in blockers and the best results were in liberos. However, this test has revealed a significant influence of $\mathrm{BH}$ on $\mathrm{FI}$ in VOL and a significant influence of BMI on FI in CON.

Concerning the efficiency $(\eta)$ of the conversion of mechanical work into mechanical energy for VOL and CON, relatively low values of $23.67 \pm 2.64 \%$ in VOL and $19.83 \pm 3.17 \%$ in $\mathrm{CON}$ were calculated. The difference between both groups was significant $(p=.01)$. The best $\eta$ results were observed in setters and the weakest in blockers.

\section{Discussion}

Controlling the basic anthropometric parameters in the population of top athletes has practical use in the training and talent identification processes but also in comparing the process with the general population (Norton \& Olds, 2001). This study aimed to analyse the relationship between jumping performance and basic anthropometric parameters in a group of female volleyball players and a control group of university students. Also, a new jumping performance parameter such as the efficiency of the transformation of an athlete's mechanical work during take-off into mechanical

Table 3 Regression analysis for SJ, CMJ and CJ

\begin{tabular}{|c|c|c|c|c|c|c|c|c|c|c|}
\hline \multirow[b]{2}{*}{ Variable } & \multicolumn{5}{|c|}{ VOL } & \multicolumn{5}{|c|}{ CON } \\
\hline & $b_{0}$ & $b_{1}$ & $b_{2}$ & $b_{3}$ & $R^{2}$ & $b_{0}$ & $b_{1}$ & $b_{2}$ & $b_{3}$ & $R^{2}$ \\
\hline SJ hj & 67.99 & -14.64 & -0.078 & 0.107 & -.007 & -92.08 & 0.567 & -0.424 & 0.165 & .178 \\
\hline CMJ hj & 84.10 & -27.55 & 0.031 & 0.152 & -.007 & -88.31 & 61.05 & -0.328 & 1.679 & .168 \\
\hline CJ hj $j_{\max }$ & 27.55 & 7.70 & -0.182 & 0.453 & .102 & -83.32 & 68.78 & -0.345 & 0.780 & .346 \\
\hline$C J \mathrm{hj}_{\mathrm{ave}}$ & 0.99 & 17.29 & -0.095 & 0.301 & -.006 & -127.51 & 89.12 & -0.363 & 1.020 & .576 \\
\hline $\mathrm{CJ} \mathrm{CT}_{\text {ave }}$ & -586.40 & 757.95 & -0.793 & 4.238 & .015 & 1026.10 & 519.30 & 7.167 & -63.67 & .000 \\
\hline CJ $\eta$ & 34.55 & -3.82 & -0.058 & 0.001 & -.210 & -38.93 & 23.71 & -0.269 & 1.534 & .178 \\
\hline $\mathrm{CJ} \mathrm{FI}$ & -48.80 & 56.32 & 0.421 & -0.445 & .442 & -169.96 & 139.83 & -0.682 & 2.159 & .330 \\
\hline
\end{tabular}

Note. $\mathrm{SJ}=$ squat jump; $\mathrm{CMJ}=$ countermovement jump; $\mathrm{CJ}=$ continuous jumps; $\mathrm{VOL}=$ volleyball players; $\mathrm{CON}=$ control group; $\mathrm{b}_{0 . . .3}=$ regression coefficients; $R^{2}=$ coefficient


the $\mathrm{CJ} ; \mathrm{CJ} \eta=$ efficiency in the $\mathrm{CJ} ; \mathrm{CJ} \mathrm{FI}=$ fatigue index in the $\mathrm{CJ}$.

Table 4 Spearman correlation coefficients between the height of the jump in SJ and CMJ and the anthropometric parameters

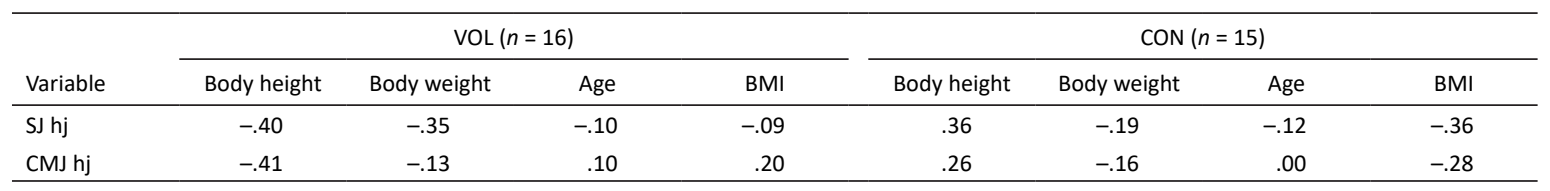

Note. $\mathrm{SJ}=$ squat jump; $\mathrm{CMJ}=$ countermovement jump; $\mathrm{VOL}=$ volleyball players; $\mathrm{CON}=$ control group; $\mathrm{BMI}=$ body mass index; $\mathrm{hj}=$ height of the jump.

Table 5 Spearman correlation coefficients between the continuous jumps parameters and the anthropometric parameters

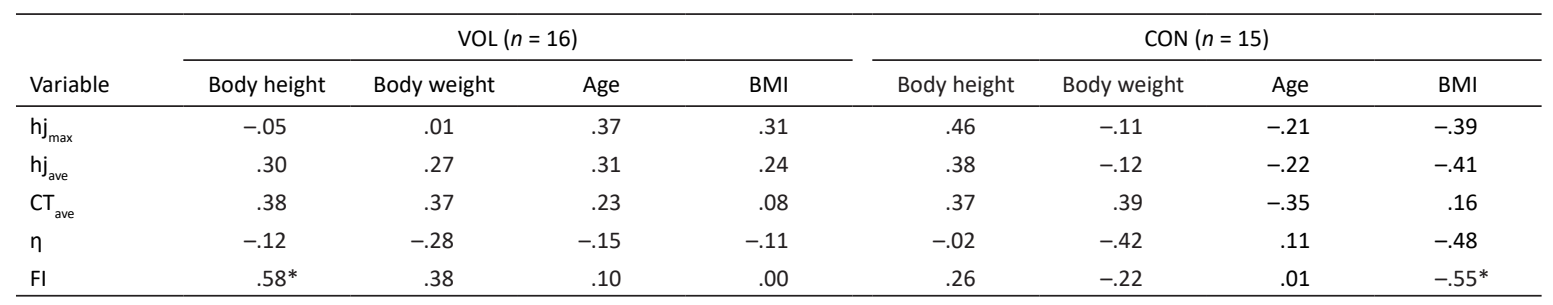

Note VOL = volleyball players $\mathrm{CON}=$ control group; $\mathrm{BMI}=$ body mass index; $\mathrm{hj}_{\max }=$ maximal height of the jump; $\mathrm{hj}_{\text {ave }}=\operatorname{average~height~of~the~jump;~} \mathrm{CT}_{\text {ave }}=\mathrm{aver}$ age contact time; $\eta=$ efficiency; $\mathrm{FI}=$ fatigue index in continuous jumps. ${ }^{*} p<.05$. 
energy of the flight phase during the 45-s CJ was observed and correlated with basic anthropometric parameters.

Concerning $\mathrm{BH}$, the highest values in the VOL were found in the position of middle blockers and the lowest in the libero position. These results follow each player's role in the game and are similar to the previous studies (MielgoAyuso et al., 2015; Palao et al., 2014). Bankovic et al. (2018) reported an average height of $187.9 \mathrm{~cm}$ in the four most successful teams at the Rio 2016 Olympic Games. Our results showed lower average $\mathrm{BH}$, but observed participants were of lower performance level when only two participants were members of the national team. According to scientific evidence (Bankovic et al., 2018; MielgoAyuso et al., 2015; Palao et al., 2014), top elite women volleyball players represent the ectomorph body type, and the volleyball players are taller, comparing to the general population (Dopsaj \& Dojordjevic-Nikic, 2016) which is in accordance with our results.

When analysing jumping performance in SJ and CMJ, higher overall values were observed in VOL than in CON. However, the results of CON were quite good when compared with another study (Battaglia et al., 2014). Different facts might explain this. Firstly, although the CON group represents the general population, some subjects might be active athletes who have developed jumping abilities in the past. Secondly, the CON group attended physical activity sessions $2 \mathrm{hrs} /$ week at the university.

Statistical analysis in the VOL group did not show a significant correlation between hj and any anthropometric parameters. The effect of $\mathrm{BH}$ was not confirmed when the highest hj in SJ was found in the smallest players in the libero position. The agility of libero players might explain it, but these are only our speculations because we did not evaluate agility. In $\mathrm{CON}$, the only moderate effect of $\mathrm{BH}$ on hj and the very low effect of BW and age on hj were observed.

The correlation between hj in CMJ and anthropometric characteristics in VOL and CON was similar to SJ when the only moderate effect of $\mathrm{BH}$ in $\mathrm{CON}$ was observed. In VOL, only a very low correlation with $\mathrm{BH}, \mathrm{BW}$ and age was found. The highest hj was observed in spikers, but these values were only slightly higher than those in liberos. Very good results of liberos can be explained by a very good ratio of muscle fast fibres in this position. According to Kistler software (based on the sum of the total flight times, and the number of jumps performed during CJ), the ratio of fast muscle fibres was the highest among these players. However, this variable was not included in the analysis of the presented study). The lowest hj in both single vertical tests were found in the blocker position, where the effect of the knee pre-stretch was very low. It is in accordance with the study of Trajković et al. (2011). In addition, Nikolaidis et al. (2015) also reported the weakest results in jumping height in blockers. He explained these results by the fact that blockers, due to their height and arm length and to the height of the female volleyball net $(224 \mathrm{~cm})$, are relatively easy to get high above the net (blocking height is about $295 \mathrm{~cm}$ ). They reach the ball higher than smaller players with higher jumping height. In addition, body height is essential for middles wherein these taller athletes can move laterally at the net faster for blocking thanks to their lengthy extremities (Sheppard et al., 2009). However, many factors impact the success rate in volleyball, and the vertical jump is a very respectable parameter for all players (except liberos). Tall blockers usually have long upper extremities lengths, and it is not always necessary for them to jump as high as possible during the defence. They have to adapt their jump height according to the attack variations of the rival. Blockers are defensive players and often attack through the middle of the net and have to get around the block of the rival or hit the ball over the top of the blocker's hands. Team-average jump height did not change throughout the season. However, competition volume is negatively associated with changes in CMJ height. Such decreases in $\mathrm{CMJ}$ height over the season occurred in players who played large numbers of sets (Kipp et al., 2021).

Analysing jumping performance in CJ, higher values of maximal height of the jump and average height of jump occurred in VOL than in CON. This trend was to be expected because vertical jump height is a determining factor in elite volleyball performance (Sheppard et al., 2012). The best $\mathrm{hj}_{\max }$ reached liberos, and the best hj $\mathrm{j}_{\text {ave }}$ spikers reflecting a very good level of anaerobic characteristics. However, the height of the jump decreases with growing fatigue, even in highly trained athletes (Sayavera et al., 2017). The weakest results in $\mathrm{hj}_{\max }$ and hj $\mathrm{j}_{\text {ave }}$ were in setters, though setters are playmakers and they play the ball practically the most often. Their total jump demands during match conditions are the highest (Sheppard et al., 2009). According to regression analysis, only a low correlation between anthropometric parameters and hj in VOL was observed. Besides moderate correlation between $\mathrm{BH}, \mathrm{BW}$ and $\mathrm{hj}_{\max }$ and strong correlation of $\mathrm{BH}$ with $\mathrm{hj}_{\mathrm{ave}}$ in $\mathrm{CON}$ was found. This can confirm the hypothesis about the positive effect of $\mathrm{BH}$ on repeated jumping height during the 45-s test in female university students. However, in the case of BW, the (negative) effect was only moderate. From the perspective of volleyball coaches, $\mathrm{BW}$ in the monitored VOL group had no significant effect on jumping performance.

The results of contact time during CJ have shown a shorter duration in VOL than in CON, but in both groups, there was a gradual increase in contact time with the force plate in the course of a 45-s CJ. This fact means that in CJ, there is a certain degree of work under muscular fatigue conditions. The shortest ground contact was found in liberos and the longest in blockers, who are, according to Sheppard et al. (2009), inherently slower. No correlation with any anthropometric parameters, neither in VOL nor in CON, was found.

Concerning other jumping performance parameters such as the efficiency of the transformation of an athlete's mechanical work during take-off into mechanical energy of the flight phase during the 45-s CJ, VOL achieved higher results than CON. The best efficiency was observed in setters, who are the players with the highest number of jumps during the match. The worst values were found in blockers. Although at the beginning of the test were the values up to $50 \%$, there was a gradual decrease in efficiency during the test in all participants. In VOL, only a very low correlation between $\mathrm{BH}, \mathrm{BW}$, and age and $\eta$ was found. In CON 
only a moderate correlation with BW was found. Like the efficiency of any machine, the efficiency of mechanical work is reduced by the internal friction in muscles and between individual muscle groups and joints (Jandova et al., 2017). The decrease in efficiency due to the fatigue can be explained because the force exerted by the subject's feet does not only contribute to the jumping take-off but also to the maintenance of a stable position before take-off. Therefore, $\eta$ in females is usually decreasing with increasing fatigue, so subjects should pay more attention to the achievement of the proper squat position and to stabilising their posture and focusing less on their take-off (Jandova et al., 2017).

When analysing FI, differences between VOL and CON were surprisingly not as high as could be expected. The correlation with $\mathrm{BH}, \mathrm{BW}$ and age in VOL was low. Only a moderate effect of BH on FI was confirmed. The most fatigue was observed in blockers, and the best results were in liberos.

However, some considerations should be mentioned in this study with several limitations. One of the limitations might be a small number of VOL participants. In addition, it should be noted that the sports activities of the CON group were not monitored, and the female participants for this group were selected among students, who voluntarily attend physical education lessons and were present on the day of measurement. Besides these limitations, several aspects should be taken into account during training and talent identification processes.

\section{Conclusions}

This study did not find any significant correlations between age, body height and body weight and jumping performance in squat and countermovement jumps in female volleyball players. In continuous jumps, a statistically significant correlation was found between body height and fatigue index in female volleyball players. Outstanding results achieved players in libero position, and the weakest results were found in blockers. Nowadays, many volleyball coaches are used to identifying talented individuals mainly according to body height, but it is important that the talent identification process must also consider jumping abilities and agility (although agility was not evaluated in our study). These parameters should also help coaches choose the optimal players for the appropriate position and role in the team. With respect to the high fatigue index values, and the length of the game and the whole season, we recommend improving not only jumping abilities and agility but also paying attention to endurance abilities during the preparatory period.

\section{Conflict of interest}

The authors report no conflict of interest.

\section{References}

Bankovic, V., Dopsaj, M., Terzic, Z., \& Nesic, G. (2018). Descriptive body composition profile in female Olympic volleyball medalists defined using multichannel bioimpedance measurement: Rio 2016 team case study. International Journal of Morphology, 36(2), 699-708. https://doi.org/10.4067/S0717-95022018000200699 Battaglia, G., Paoli, A., Bellafiore, M., Bianco, A., \& Palma, A. (2014). Influence of a sport-specific training background on vertical jumping and throwing performance in young female basketball and volleyball players. Journal of Sports Medicine and Physical Fitness, 54(5), 581-587. https://www.minervamedica.it/en/ iournals/sports-med-physical-fitness/article.php?cod=R40Y2014N05A0581

Bencke, J., Damsgaard, R., Saekmose, A., Jorgensen, P., Jorgensen, K., \& Klausen, K. (2002). Anaerobic power and muscle strength characteristics of 11 years old elite and non-elite boys and girls from gymnastics, team handball, tennis and swimming. Scandinavian Journal of Medicine and Science in Sports, 12(3), 171-178. https://doi.org/10.1034/j.1600-0838.2002.01128.x

Bosco, C., Luhtanen, P., \& Komi, P. V. (1983). A simple method for measurement of mechanical power in jumping. European Journal of Applied Physiology and Occupational Physiology, 50(2), 273-282. https://doi.org/10.1007/BF00422166

Dopsaj, M., \& Dojordjevic-Nikic, M. (2016). Basic body structure characteristics of the elite Serbian athletes measured by the method of multisegmental bioelectrical impedance. Serbian Science Today, 1(2), 276-284.

Gabbett, T., Georgieff, B., \& Domrow, N. (2007). The use of physiological, anthropometric, and skill data to predict selection in a talent-identified junior volleyball squad. Journal of Sports Sciences, 25(12), 1337-1344. https://doi org/10.1080/02640410601188777

Giannopoulos, N., Vagenas, G., Noutsos, K., Barzouka, K., \& Bergeles, N. (2017). Somatotype, level of competition, and performance in attack in elite male volleyball. Journal of Human Kinetics, 58, 131-140. https://doi.org/10.1515/ hukin-2017-0082

Haugen, T. A., Breitschädel, F., Wiig, H., \& Seiler, S. (2021). Countermovement jump height in national-team athletes of various sports: A framework for practitioners and scientists. International Journal of Sports Physiology and Performance, 16(2), 184-189. https://doi.org/10.1123/iispp.2019-0964

Jandova, S., \& Janura, M. (2019). Jumping performance and take-off efficiency in two different age categories of female volleyball players. Acta of Bioengineer ing and Biomechanics, 21(2), 55-61. https://doi.org/10.5277/ABB-01328-2019-02

Jandova, S., Musilek, M., Martin, A. J., Cochrane, D., \& Rozkovec, J. (2017). Take-off efficiency: Transformation of mechanical work into kinetic energy during the Bosco test. Human Movement, 18(3), 34-39. https://doi.org/10.1515/ humo-2017-0023

Kipp, K., Kiely, M., \& Geiser, C. (2021). Competition volume and changes in countermovement jump biomechanics and motor signatures in female collegiate volleyball players. Journal of Strength and Conditioning Research, 35(4), 970-975. https://doi.org/10.1519/JSC.0000000000003967

LaPorta, J. W., Brown, L. E., Coburn, J. W., Galpin, A. J., Tufano, J. J., Cazas, V. L., \& Tan, J. G. (2013). Effects of different footwear on vertical jump and landing parameters. Journal of Strength and Conditioning Research, 27(3), 733-737. https://doi.org/10.1519/JSC.0b013e318280c9ce

Lidor, R., Falk, B., Arnon, M., Cohen, Y., Segal, G., \& Lander, Y. (2005). Measurement of talent in team handball: The questionable use of motor and physical tests. Journal of Strength and Conditioning Research, 19(2), 318-325. https:// journals.Iww.com/nsca-jscr/Fulltext/2005/05000/MEASUREMENT OF TALENT IN TEAM HANDBALL THE.14.aspX

Lidor, R., \& Ziv, G. (2010). Physical characteristics and physiological attributes of adolescent volleyball players - A review. Pediatric Exercise Science, 22(1), 114-134. https://doi.org/10.1123/pes.22.1.114

Malá, L., Malý, T., Záhalka, F., \& Bunc, V. (2010). The profile and comparison of body composition of elite female volleyball players. Kinesiology, 42(1), 90-97. https://hrcak.srce.hr/54246

Malousaris, G. G., Bergeles, N. K., Barzouka, K. G., Bayios, I. A., Nassis, G. P., \& Koskolou, M. D. (2008). Somatotype, size and body composition of competitive female volleyball players. Journal of Science and Medicine in Sport, 11(3), 337-344. https://doi.org/10.1016/i.jsams.2006.11.008

Markovic, G., Dizdar, D., Jukic I., \& Cardinale, M. (2004). Reliability and factorial validity of squat and countermovement jump tests. Journal of Strength and Conditioning Research, 18(3), 551-555. https://journals.Iww.com/nsca-iscr/fulltext/2004/08000/reliability and factorial validity of squat and.28.aspx

Mielgo-Ayuso, J., Calleja-Gonzáles, J., Clemente-Suárez, V. J., \& Zourdos, M. C. (2015). Influence of anthropometric profile on physical performance in elite female volleyballers in relation to playing position. Nutricion Hospitalaria, 31(2), 849-857. https://doi.org/10.3305/nh.2015.31.2.7658

Nikolaidis, P. T. (2013). Body mass index and body fat percentage are associated with decreased physical fitness in adolescent and adult female volleyball players. Journal of Research in Medical Sciences, 18(1), 22-26.

Nikolaidis, P. T., Afonso, J., Buško, K., Ingebrigtsen, J., Chtourou, H., \& Martin, J. J. (2015). Positional differences of physical traits and physiological characteristics in female volleyball players - The role of age. Kinesiology, 47(1), 75-81. https:// hrcak.srce.hr/140254

Nikolaidis, P. T., \& Ingebrigtsen, J. (2013). Physical and physiological characteristics of elite male handball players from teams with a different ranking. Journa of Human Kinetics, 38, 115-124. https://doi.org/10.2478/hukin-2013-0051

Norton, K., \& Olds, T. (2001). Morphological evolution of athletes over 20th century: Causes and consequences. Sports Medicine, 31(11), 763-783. https://doi. org/10.2165/00007256-200131110-00001

Palao, J. M., Manzanares, P., \& Valadés, D. (2014). Anthropometric, physical, and age differences by the players position and the performance level in volleyball. Journal of Human Kinetics, 44, 223-236. https://doi.org/10.2478/hukin-2014-0128 
Pavillon, T., Tourny, C., Ben Aabderrahman, A., Salhi, I., Zouita, S., Rouissi, M., Hackney, A. C., Granacher, U., \& Zouhal, H. (2021). Sprint and jump performances in highly trained young soccer players of different chronological age: Effect of linear vs. CHANGE-OF-DIRECTION sprint training. Journal of Exercise Science \& Fitness, 19(2), 81-90. https://doi.org/10.1016/i.jesf.2020.10.003

Santos, D. A., Dawson, J. A., Matias, C. N., Rocha, P. M., Minderico, C. S., Allison, D. B., Sardinha, L. B., \& Silva, A. M. (2014). Reference values for body composition and anthropometric measurements in athletes. PLOS ONE, 9(5), Article e97846. https://doi.org/10.1371/journal.pone.0097846

Sayavera, J. B., Nikolaidis, P. T., Camacho-Cardenosa, A., Camacho-Cardenosa, M., Timón, R., \& Olivares, P. R. (2017). Acute effect of block jumps in female volleyball players: The role of performance level. Sports, 5(2), Article 30. https:// doi.org/10.3390/sports5020030

Sheppard, J. M., Gabbett, T. J., \& Stanganelli, L. C. R. (2009). An analysis of playing positions in elite men's volleyball: Considerations for competition demands and physiologic characteristics. Journal of Strength and Conditioning Research, 23(6), 1858-1866. https://doi.org/10.1519/JSC.0b013e3181b45c6a

Sheppard, J. M., Nolan, E., \& Newton, R. U. (2012). Changes in strength and power qualities over two years in volleyball players transitioning from junior to senior national team. Journal of Strength and Conditioning Research, 26(1), 152-157. https://doi.org/10.1519/JSC.0b013e31821e4d5b
Skazalski, C., Whiteley, R., \& Bahr, R. (2018). High jump demands in professional volleyball - large variability exists between players and player positions. Scandinavian Journal of Medicine \& Science in Sports, 28(11), 2293-2298. https:// doi.org/10.1111/sms.13255

Trajković, N., Milanović, Z., Sporič, G., \& Radisavljević, M. (2011). Positional differences in body composition and jumping performance among young elite volleyball players. Acta Kinesiologica, 5(1), 62-66. http://www.actakin.com/PDFS/ BR0501/SVEE/04\%20CL\%2013\%20NT.pdf

Vaeyens, R., Lenoir, M., Williams, A. M., \& Philippaerts, R. M. (2008). Talent identification and development programmes in sport: Current models and future directions. Sports Medicine, 38(9), 703-714. https://doi. org/10.2165/00007256-200838090-00001

Valleser, C. W. M., Bersola, K. A. R., Mallari, M. F. T., Papa, E. L. V., Diaz, F. C. B., Maghanoy, M. L. A., \& Lariosa, C. J. D. (2018). Anthropometric profile of elite women's volleyball players in the Philippines. Turkish Journal of Kinesiology, 4(2), 53-57. https://doi.org/10.31459/turkikin.417481r

Ziv, G., \& Lidor, R. (2010). Vertical jump in female and male volleyball players: A review of observational and experimental studies. Scandinavian Journal of Medicine and Science in Sports, 20(4), 556-567. https://doi. org/10.1111/i.1600-0838.2009.01083.x 